\title{
DERECHOS DE LA PERSONA HUMANA: EL DERECHO DEL EXTRANJERO PRIVADO DE LIBERTAD A LA ASISTENCIA CONSULAR ${ }^{1}$
}

\section{DIREITOS FUNDAMENTAIS DA PESSOA HUMANA: O DIREITO DO PRESO ESTRANGEIRO À ASSISTÊNCIA CONSULAR}

\section{FUNDAMENTAL RIGHTS OF THE HUMAN PERSON: THE RIGHT OF THE FOREIGN DETAINEE TO CONSULAR ASSISTANCE}

\begin{abstract}
VERA LÚCIA VIEGAS-LIQUIDATO
Doctora en Derecho Internacional por la Universidad de São Paulo (tesis doctoral escrita en la Universidad de Granada). Especialista en Derecho de la Integración por la Università Tor Vergata (Roma). Especialista en Derecho Internacional Humanitario por el Comité de la Cruz Roja Internacional (Sección Cono Sur). Profesora (pre y postgrado) e Investigadora en Derecho Internacional en la Facultad de Derecho de São Bernardo do Campo (São Paulo).
\end{abstract}

\section{RESUMEN}

En este trabajo se hará inicialmente una evolución histórica del Derecho Internacional de los Derechos Humanos, tomando el marco teórico referencial de Karel Vasak, Norberto Bobbio y Antonio Augusto Cançado Trindade, para abordar la discusión del derecho internacional de los derechos humanos en generaciones / dimensiones. A continuación se abordarán el estado de arte, límites y desafíos del derecho fundamental del extranjero privado de la libertad a la asistencia consular. Se

\footnotetext{
1 Ponencia presentada en el XXI Congreso Internacional de Historia de los Derechos Humanos, Universidad de Salamanca, en el mes de julio de 2018. La segunda parte del trabajo fue publicada en portugués en: VIEGAS LIQUIDATO, 2018, p. 319-337.
} 
plantearán cuestiones como, si al privado de la libertad no se le ofreció asistencia consular, qué implicaciones generaría para la garantía del debido proceso legal e incluso la posibilidad de la nulidad de una sentencia penal condenatoria. Se analizará jurisprudencia internacional al respecto, incluida la opinión consultiva de la Corte Interamericana de Derechos Humanos.

PALABRAS-CLAVE: Derecho Internacional de los Derechos Humanos; Derechos Fundamentales de la Persona Humana; Derecho a la asistencia consular; Garantías del debido proceso legal.

\section{RESUMO}

Neste trabalho far-se-á, inicialmente, uma evolução histórica do direito internacional dos direitos humanos, utilizando-se o referencial teórico de Karel Vasak, Norberto Bobbio e Antonio Augusto Cançado Trindade, para pautar a discussão do direito internacional dos direitos humanos em gerações/dimensões. Em seguida, analisar-seão os desafios, limites, estado de arte, do direito fundamental do preso estrangeiro à assistência consular. Levantar-se-ão questões como, caso ao preso estrangeiro não Ihe tenha sido oferecida a assistência consular, as implicações que isso geraria para as garantias do devido processo legal e até mesmo para a nulidade de uma sentença penal condenatória. Considerar-se-á jurisprudência internacional a respeito, incluindo a opinião Consultiva da Corte Interamericana de Direitos Humanos.

PALAVRAS-CHAVE: Direito Internacional dos Direitos Humanos; Direitos Fundamentais da Pessoa Humana; Direito à assistência consular; Garantias do devido processo legal.

\section{ABSTRACT}

In this work, initially, a historical evolution of the international law of the human rights will be made, using the theoretical reference of Karel Vasak, Norberto Bobbio and Antonio Augusto Cançado Trindade, to guide the discussion of international law of the 
human rights in generations / dimensions. Afterwards, will be analyzed the challenges, limits, state of art, the fundamental right of the foreign detainee to consular assistance. Questions will arise as, if the detainee has not been notified of his right to consular assistance, the implications that this would generate for the guarantees of the due process of law. International law cases will be considered, including the Advisory Opinion of the Inter-American Court of Human Rights.

KEYWORDS: International Human Rights Law; Fundamental Rights of the Human Person; Right to consular assistance; Guarantees of the due process of law.

\section{INTRODUCIÓN}

El tránsito del Derecho Internacional Clásico al Derecho Internacional contemporáneo se refleja nítidamente en la conquista de los derechos humanos. De la existencia de las monarquías absolutistas, con el Estado-Nación como único titular de una soberanía absoluta e ilimitada, se pasa a la construcción gradual del Estado Democrático de Derecho, frente al cual el individuo tiene derechos contra el Estado (derecho a la vida, libertad), derechos en el Estado (derechos de participar del Estado: derechos políticos) y derechos por medio del Estado (derechos económicos y sociales).

Este trabajo inicia con el análisis de la evolución histórica de las clasificaciones del Derecho Internacional de los Derechos Humanos, siguiendo el marco teórico referencial de Karel Vasak, Norberto Bobbio y Antonio Augusto Cançado Trindade, discutiendo los términos generaciones / dimensiones. Eso resulta útil porque el objeto central de este estudio se centra en uno de los derechos fundamentales de la persona humana, es decir, el derecho del preso extranjero a la asistencia consular.

Como ese derecho está explícitamente mencionado en el artículo 36, §1, "b", de la Convención de Ginebra sobre las Relaciones Consulares, en el ítem 1.2 del presente trabajo se elucidarán cuestiones de los bastidores de esa Convención, incluso con su contexto histórico y el trámite de su negociación. 
El ítem 1.4 se dedicará al contenido material de la asistencia consular, con su reflejo - ítem 2 - en la Opinión Consultiva o 16 de la Corte Interamericana de Derechos Humanos. Mientras que en el ítem 2.3 será dedicado a relacionar el derecho a la información sobre la asistencia consular con las garantías judiciales: el principio del due process of law y, más específicamente, la efectividad del debido proceso legal.

Lo que se investiga en este estudio es el estado de arte, los límites y desafíos del derecho fundamental a la asistencia consular del extranjero privado de la libertad. Se analizarán cuestiones como la falta de notificación al preso extranjero de su derecho a la asistencia consular; las implicaciones que esta situación generaría para la garantía del debido proceso legal e, incluso, la oponibilidad de una nulidad de la sentencia penal condenatoria.

\section{DERECHO DEL EXTRANJERO A LA INFORMACIÓN SOBRE ASISTENCIA CONSULAR}

El presente artículo tiene por objeto analizar, en referencia a los derechos fundamentales de la persona humana, el derecho a la asistencia consular disciplinada en el artículo 36 §1ㅇ "b" de la Convención de Viena sobre Relaciones Consulares de $1963 .^{2}$

\footnotetext{
${ }^{2}$ La Convención de Viena sobre Relaciones Consulares fue celebrada en Viena el día 24/04/1963, siendo sido firmada por Brasil en esa fecha. Fue aprobada por Brasil mediante Decreto Legislativo $\mathrm{n}$. 06, de 05/04/1967. Brasil depositó su instrumento de ratificación en la ONU el 11/05/1967. Fue promulgada en Brasil por el Decreto n. 61.078, de 26/07/1967 e publicada en el Diário Oficial da União el 28/07/1967. Entró en vigor en Brasil el 10/06/1967, en los términos del Artículo 77, § 20: "2. Para cada Estado que ratifique la Convención o se adhiera a ella después de haber sido depositado el vigesimosegundo instrumento de ratificación o de adhesión, la Convención entrará en vigor el trigésimo día a partir de la fecha en que tal Estado haya depositado su instrumento de ratificación o de adhesión". En cuanto a los instrumentos jurídicos sobre relaciones consulares, conviene mencionar que, además de la Convención de Viena sobre Relaciones Consulares de 1963, se firmaron también el Protocolo Facultativo de la Convención de Viena sobre Relaciones Consulares sobre la Adquisición de Nacionalidad (Viena, 24 de abril de 1963) y el Protocolo Facultativo de la Convención de Viena sobre Relaciones Consulares sobre la Jurisdicción Obligatoria para la Solución de Controversias (Viena, 24 de abril de 1963).
} 
Tal asistencia consular debe ser realizada por el Consulado a su respectivo nacional que haya sido "preso, encarcelado, puesto en prisión preventiva o detenido de cualquier otra manera" ${ }^{3}$ por el Estado acreditado. ${ }^{4}$ Veamos:

\begin{abstract}
Artículo 36 - Comunicación con los nacionales del Estado que envía 1. Con el fin de facilitar el ejercicio de las funciones consulares relacionadas con los nacionales del Estado que envía: a) los funcionarios consulares podrán comunicarse libremente con los nacionales del Estado que envía y visitarlos. Los nacionales del Estado que envía deberán tener la misma libertad de comunicarse con los funcionarios consulares de ese Estado y de visitarlos; b) si el interesado lo solicita, las autoridades competentes del Estado receptor deberán informar sin retraso alguno a la oficina consular competente en ese Estado cuando, en su circunscripción, un nacional del Estado que envía sea arrestado de cualquier forma, detenido o puesto en prisión preventiva. Cualquier comunicación dirigida a la oficina consular por la persona arrestada, detenida o puesta en prisión preventiva, le será asimismo transmitida sin demora por dichas autoridades, las cuales habrán de informar sin dilación a la persona interesada acerca de los derechos que se le reconocen en este apartado; c) los funcionarios consulares tendrán derecho a visitar al nacional del Estado que envía que se halle arrestado, detenido o en prisión preventiva, a conversar con él y a organizar su defensa ante los tribunales. Asimismo, tendrán derecho a visitar a todo nacional del Estado que envía que, en su circunscripción, se halle arrestado, detenido o preso en cumplimiento de una sentencia. Sin embargo, los funcionarios consulares se abstendrán de intervenir en favor del nacional detenido, cuando éste se oponga expresamente a ello. 2. Las prerrogativas a las que se refiere el párrafo 1 de este artículo se ejercerán con arreglo a las leyes y reglamentos del Estado receptor, debiendo entenderse, sin embargo, que dichas leyes y reglamentos no impedirán que tengan pleno efecto los derechos reconocidos por este artículo.
\end{abstract}

La problemática que se presenta aquí es la de saber si esos extranjeros en esas situaciones tienen derecho a ser informados acerca de la asistencia consular; es decir: ¿las autoridades del Estado receptor tienen la obligación de informar a esos extranjeros de ese derecho?

Este asunto se presenta debido a la redacción del Artículo 36, $\S 1$ ํㅜ "b", que menciona literalmente que las autoridades locales del Estado receptor deben informar a la autoridad consular competente, "si el interesado lo solicita". Lo que se pregunta

\footnotetext{
${ }^{3}$ Se utiliza el término preso extranjero para referirnos tanto al supuesto de una persona que, estando fuera de su país de origen, es privada de libertad por las autoridades competentes del Estado en el que se encuentra, por la presunta comisión de un hecho ilícito; como al caso del extranjero que ha sido juzgado penalmente y declarado culpable en un Estado que no es el suyo.

${ }^{4}$ Estado acreditado o Estado receptor es el Estado que "recibe", es decir, aquel en cuyo territorio se instala el cuerpo consular (es el Estado anfitrión). El "Estado acreditante" o "Estado que envía" es aquel que mantiene el cuerpo consular, enviando sus representantes.
} 
es si el extranjero en cuestión no sabe que tiene ese derecho - que es lo que ocurre en la mayoría de las veces -. ¿Cómo puede un extranjero solicitar una asistencia a la cual no sabe que tiene derecho?

El extranjero muchas veces no habla el idioma del Estado receptor y no tiene abogado. ¿Sin la asistencia consular podrá eficazmente defenderse en juicio? ¿Sin la asistencia consular no habría violación al principio del debido proceso legal?

Antes de centrarnos en la regulación del derecho a la asistencia consular, su interpretación jurisprudencial y las implicaciones para los casos de violación de dicho derecho, se hace menester establecer algunas consideraciones sobre la concepción de los derechos fundamentales de la persona humana como "generaciones" o como "dimensiones".

\subsection{CLASIFICACIÓN DE LOS DERECHOS FUNDAMENTALES DE LA PERSONA HUMANA EN GENERACIONES}

Karel Vasak, figura como un gran exponente de la clasificación de los derechos fundamentales de la persona humana en generaciones ${ }^{5}$. En la clase magistral dictada en el Instituto Internacional de Derechos Humanos de Estrasburgo en 1979 (VASAK, 1979) ${ }^{6}$, dividió los derechos humanos en generaciones, al referirse al lema de la Revolución Francesa. La primera generación son los derechos de libertad (derechos civiles y políticos); la segunda generación corresponde a los derechos de igualdad (los derechos económicos, sociales y culturales) y la tercera generación que estaría ahora en desarrollo en la sociedad internacional - los derechos de la fraternidad (derechos de solidaridad, en especial el derecho al desarrollo, a la paz y al medio ambiente). A partir de ahí, Noberto Bobbio habría seguido esa "tesis" y creado su propia interpretación de los derechos humanos divididos en generaciones (BOBBIO, 1992, p.32-33).

\footnotetext{
${ }^{5}$ En este trabajo se utilizan las expresiones derechos humanos, derechos fundamentales de la persona humana, Derecho Internacional de los Derechos humanos como sinónimos, aunque no son exactamente correspondientes.

${ }^{6}$ Vide también, com relación de esa aula magistral, las afirmaciones que Antonio Augusto Cançado Trindade 2000. (DHNET, 2000)
} 
Antes de esa clase magistral, Karel Vasak ya se refería a las generaciones de derechos humanos en la obra publicada en 1977, en los siguientes términos:

\begin{abstract}
La primera generación concierne a los derechos negativos (...) ["negative" rights], en el sentido que el respeto a los correspondientes poderes formativos implica una no interferencia del Estado con las libertades individuales y no corresponde exactamente a los derechos civiles y políticos. La segunda generación, por su parte, exige conductas positivas del Estado para ser implementados, como es el caso de la mayor parte de los derechos sociales, económicos y culturales. La comunidad internacional está en camino de una tercera generación que puede ser llamada de derechos de solidaridad [traducción libre]. ${ }^{7}$
\end{abstract}

$Y$ es que, pese a que la clasificación de los derechos humanos en generaciones está asentada en la doctrina, hay quienes oponen reservas. ${ }^{8}$ Un gran opositor a esa clasificación es Antonio Augusto Cançado Trindade. ${ }^{9}$

Para Cançado Trindade no hay que distinguir en generaciones de derechos humanos por no existir veracidad histórica ${ }^{10}$; por no haber sucesión cronológica de los derechos humanos (uno no sucede al otro, sustituyéndolo), es decir, no desaparece

\footnotetext{
7 "The first generation concerns "negative" rights, in the sense that their respect requires that the state do nothing to interfere with individual liberties, and correspond roughly to the civil and political rights. The second generation, on the other hand, requires positive action by the state to be implemented, as is the case with most social, economic and cultural rights. The international community is now embarking upon a third generation of human rights which may be called "rights of solidarity" (VASAK, 1977, p.29). ${ }^{8}$ Sobre las críticas a la teoría de las generaciones de derechos humanos, vide, entre otros, LIMA, 2003. 9 En la "Apresentação" de la obra de Flávia Piovesan, "Direitos Humanos e o Direito Constitucional Internacional", Cançado Trindade expressa severas críticas a la clasificación de los derechos humanos en generaciones, refiriéndose a ellas como una fantasía: "a qual corresponde uma visão atomizada ou fragmentada destes últimos [os direitos] no tempo. A noção simplista das chamadas "gerações de direitos", histórica e juridicamente infundada, tem prestado um desserviço ao pensamento mais lúcido a inspirar a evolução do direito internacional dos direitos humanos. Distintamente do que a infeliz invocação da imagem analógica da "sucessão generacional" [sic] pareceria supor, os direitos humanos não se "sucedem" ou "substituem" uns aos outros, mas antes se expandem, se acumulam e fortalecem, interagindo os direitos individuais e sociais (tendo estes últimos inclusive precedido os primeiros no plano internacional, a exemplo das primeiras convenções internacionais do trabalho). O que testemunhamos é o fenômeno não de uma sucessão, mas antes, da expansão, cumulação e fortalecimento dos direitos humanos consagrados, a revelar a natureza complementar de todos os direitos humanos. Contra as tentações dos poderosos de fragmentar os direitos humanos em categorias, postergando sob pretextos diversos a realização de alguns destes (e. g., os direitos econômicos sociais) para um amanhã indefinido, se insurge o Direito dos Direitos Humanos, afirmando a unidade fundamental da concepção, a indivisibilidade e a justiciabilidade de todos os direitos humanos". CANÇADO TRINDADE, 2006, p. 31.

${ }^{10}$ En el Derecho internacional, los derechos económicos y los sociales aparecen antes, ya que las primeras convenciones de la OIT son anteriores a la ONU (surgieron en los años 20 e 30), es decir, la "primera generación" sería el derecho al trabajo, el derecho a las condiciones de trabajo; y la segunda generación correspondería a los derechos individuales, con la Declaración Americana y Universal de 1948. (CANÇADO TRINDADE, 2000).
} 
uno al "aparecer" otro"11. El autor critica esa visión atomizada de los derechos humanos como si, por ejemplo, el derecho a la no discriminación pertenece a los derechos individuales y políticos y no a los derechos económicos, sociales y culturales.

Además, todos los derechos humanos están nítidamente interconectados; no hay jerarquía entre ellos ${ }^{12}$; no hay uno que venga antes y otros pudiendo ser dejados para después; no es posible priorizar unos en detrimento de otros. Esto porque la dignidad del ser humano está formada como un todo, coherente e indivisible y el ser humano sólo se realiza en plenitud con el disfrute de los derechos humanos concebidos de un modo indivisible ${ }^{13}$.

El autor afirma: "Creio que o futuro, na proteção internacional dos direitos humanos passa pela indivisibilidade e pela inter-relação de todos os direitos, como tenho dito em meus livros" [CANÇADO TRINDADE, 2000] ${ }^{14}$.

Asimismo, es un hecho la evolución evidenciada por la sociedad internacional a lo largo de los siglos que es reflejada en el propio Derecho Internacional. Esa evolución está intrínsecamente relacionada con el cambio de concepción del propio Estado; de las monarquías absolutistas pasan a una concepción de una soberanía mitigada. Del Estado de laissez faire laissez passer, se pasa al Estado del bien estar social. Por una conclusión lógica, esa evolución repercutió en la concepción de los derechos fundamentales de la persona humana, en el aumento de nuevos derechos humanos que se unen a los que ya existían antes y obviamente, sin suplantarlos. Los derechos de la persona humana son una conquista y construcción histórica ${ }^{15}$.

\footnotetext{
11 "Na minha concepção, quando surge um novo direito, os direitos anteriores não desaparecem. Há um processo de cumulação e de expansão do corpus iuris dos direitos humanos. Os direitos se ampliam, e os novos direitos enriquecem os anteriores". (CANÇADO TRINDADE, 2000).

${ }^{12}$ George Marmelstein Lima - supra citado - entre otros autores, habla en "dimensão" de los derechos humanos. El autor afirma que: "[o] ideal é considerar que todos os direitos fundamentais podem ser analisados e compreendidos em múltiplas dimensões, ou seja, na dimensão individual-liberal (primeira dimensão), na dimensão social (segunda dimensão), na dimensão de solidariedade (terceira dimensão) e na dimensão democrática (quarta dimensão). Não há qualquer hierarquia entre essas dimensões. Na verdade, elas fazem parte de uma mesma realidade dinâmica. Essa é a única forma de salvar a teoria das dimensões dos direitos fundamentais". (LIMA, 2003).

${ }_{13}$ Sobre la indivisibilidad de los derechos humanos, vide AGBAKWA, 2000, p. 38 e ss; 129 e ss.

14 Para mayor elucidación de la doctrina de Cançado Trindade respecto a los derechos humanos, véase, entre varios otros: CANÇADO TRINDADE, 1999-2003. CANÇADO TRINDADE, 2006a.

${ }^{15}$ Según Norberto Bobbio, "os direitos do homem são direitos históricos, que emergem gradualmente das lutas que o homem trava por sua própria emancipação e das transformações das condições de vida que essas lutas produzem" (BOBBIO, 1992:32). Flavia Piovesan explica ese entendimiento de $\mathrm{BOBBIO}$ con la siguiente afirmación: "os direitos humanos não nascem todos de uma vez, nem de uma vez por todas” (PIOVESAN, 2017, p. 350).
} 
Esas conquistas históricas también no se evidencian al mismo tiempo en todo el orbe terrestre. Si en algunas regiones del globo podemos tener índices elevados de calidad de vida, sistema de salud, educación, PIB, renta per cápita, etc, no siempre eso está acompañado por el desarrollo de derechos políticos. Es decir, hay Estados que pueden ser considerados "desarrollados" económicamente, pero políticamente son dominados por regímenes totalitarios en los cuales, v. g., el derecho al voto no es extendido a las mujeres. Esto pone en jaque la teoría de las "generaciones" de derechos humanos, pues ¿cómo podría haber surgido la segunda generación (económicos, sociales, ...) sin haber habido la generación anterior?

No obstante existan críticas fundamentadas a la clasificación de los derechos humanos en generaciones - como la realizada en el párrafo anterior - muchas de esas críticas no tienen fundamento. No creemos, por ejemplo, que los autores que hablan de generaciones tuvieran en algún momento la idea de que nuevos derechos humanos surgen sustituyendo a los anteriores. Es una cuestión de pura lógica. Si el derecho concede hoy a un individuo el derecho de exigir al Estado que le de educación de calidad, morada digna, etc., de modo alguno eso significa que ese mismo individuo no goza más del derecho a la vida, a la libertad, etc.

Preferimos la expresión dimensiones de los derechos humanos. Entendemos que el análisis de los derechos humanos en "dimensiones" atendería inclusive a la necesidad didáctica del estudio de los mismos, pero pensamos que es perfectamente posible que se pueda convivir con el término "generaciones" de los derechos humanos, desde que eso sea interpretado de tal forma de entender el núcleo cohesionado e indivisible de la dignidad de la persona humana, de la no jerarquización de los derechos humanos, etc., lo que pensamos que todos los que se valen del término "generaciones", igualmente creen y defienden.

Presentadas como han sido esas consideraciones acerca de la clasificación de los derechos humanos, pasamos ahora al análisis de la reglamentación del derecho a la asistencia consular.

\section{BASTIDORES DE LA CONVENCIÓN DE VIENA SOBRE RELACIONES CONSULARES (1963)}


Como el objeto central de este estudio se centra en la interpretación e implementación del dispositivo de la Convención de Viena sobre Relaciones Consulares (precisamente su Artículo $36, \S 1^{\circ}$, "b"), deben ser presentadas algunas palabras acerca del trabajo de codificación del Derecho Internacional de las Relaciones Consulares que antecede a la referida Convención de Viena de 1963, anterior, incluso, a la propia ONU.

\subsection{CONTEXTO HISTÓRICO DE LA NECESIDAD DE CODIFICACIÓN DE LAS NORMAS INTERNACIONALES REFERENTES A LA ACTIVIDAD CONSULAR}

Desde tiempos inmemoriales está comprobado el contacto entre los pueblos, las civilizaciones diferentes que, desde tiempos remotos, establecen relaciones diplomáticas fomentadas, sobre todo, por la necesidad de intercambios comerciales, alianzas militares, etc ${ }^{16}$.

Igualmente, la función consular está relacionada con el desarrollo del comercio internacional. Aunque los orígenes de la institución consular remontan a la Antigua Grecia, la figura del cónsul propiamente dicha surgió por primera vez en el Siglo XII, época en la cual se elaboraban los primeros códigos sobre funciones consulares, principalmente en forma de compilaciones de Derecho marítimo (GÓMEZ ROBLEDO, 2009).

Las misiones diplomáticas permanentes se inician en la Península Itálica, en la primera mitad del Siglo XV y, a partir de allí, se expanden por Europa a partir del Siglo XV [VIEGAS LIQUIDATO, 2014: 62 e ss.]. La proliferación de las misiones diplomáticas permanentes produjo un cambio considerable en la actividad consular, lo que culminó con la publicación de la primera colección de disposiciones consulares: Ordonnance de la Marine, Colbert, 1681 [GÓMEZ ROBLEDO, 2009: 1].

El extraordinario aumento del número de consulados en los Siglos XIX y XX hizo que se hiciese necesaria la codificación de las normas consuetudinarias que

16 Sobre la evolución histórica de las relaciones diplomáticas y consulares, véase, entre otros: ANTOKOLETZ, 1948; CAHIER, 1965; FERRARA, 1936; FLORIO, 1978; FRANCHINI NETTO 1946; GENET, 1931; GIRY, 1894; MORENO PINO, 2001; NASCIMENTO E SILVA, 1969; NICOLSON, 1950; SOARES, 2001; VIEGAS LIQUIDATO, 2014. 
reglamentan la materia, especialmente en lo tocante a la actividad consular y la condición jurídica de los cónsules. Los vertiginosos cambios en la actividad social, política y económica, aliadas a las crecientes tendencias mundiales que influyen en la vida cotidiana, trajeron nuevos desafíos a la institución consular: la protección a los ciudadanos y la salvaguarda de sus intereses.

Antes de la codificación realizada por la ONU con la Convención de Viena sobre Relaciones Consulares de 1963, existían tentativas preliminares de codificar oficialmente las normas consulares internacionales por medio de la celebración de acuerdos regionales y, sobre todo, hubo un trabajo pionero realizado por la Sociedad de las Naciones, que concluyó que era no sólo conveniente, sino de suma importancia tal codificación ${ }^{17}$. No obstante esa constatación, la cuestión siguió pendiente por casi 20 años (hasta 1963) ${ }^{18}$.

\subsection{LA NEGOCIACIÓN DE LA CONVENCIÓN DE VIENA SOBRE RELACIONES CONSULARES, DE $1963 .{ }^{19}$}

Nunca está de más recordar que el análisis de cualquier Convención internacional estaría incompleto si se realiza desconectado del momento histórico del cual es fruto y del estudio de los bastidores de su negociación, así como de las actas de reuniones que culminaron con su aprobación, con los comentarios de los Estados $\mathrm{y}$ las respectivas propuestas de las delegaciones y sus votaciones; $\mathrm{y}$, cuando fuere el caso, del estudio de los comentarios de la propia Comisión de Derecho Internacional de la ONU, cuando estuviere involucrada en la misión de codificar el tema en cuestión ${ }^{20}$.

La Comisión de Derecho Internacional de la ONU consideró en 1949 la posibilidad de incluir en la pauta de su labor de codificación las relaciones e

\footnotetext{
17 La Sociedad de Naciones tenía un Comité de Expertos para la Codificación Progresiva del Derecho Internacional.

${ }^{18}$ Conviene no olvidar que, además de los antecedentes de la Convención de Viena sobre Relaciones Consulares de 1963, las disposiciones de la Convención de la Habana sobre Agentes Consulares que fue celebrada en La Habana en 1928.

${ }^{19}$ Las informaciones contenidas en este tópico fueron obtenidas en (GÓMEZ ROBLEDO, 2009).

20 Sobre la Convención de Viena sobre Relaciones Consulares de 1963, es imprescindible el estudio de esos comentarios de la propia Comisión de Derecho Internacional de la ONU, disponibles en: COMISSÃO DE DIREITO INTERNACIONAL DA ONU, 1961.
} 
inmunidades consulares. En su séptimo período de sesiones, ocurrido en Ginebra del 02 al 08 de julio de 1955, la Comisión nombró Relator Especial al Sr. Jaroslav Zourek, para que diese inicio a ese trabajo especial, examinando la cuestión y para que elaborase un conjunto de disposiciones, basado en el ius cogens y en el Derecho nacional e internacional.

El tema comenzó a ser formalmente examinado a partir de 1958. Posteriormente, se dividió el proyecto de artículos en cuatro capítulos (relaciones e inmunidades consulares; privilegios e inmunidades consulares; condición jurídica de los cónsules honorarios y sus privilegios e inmunidades y disposiciones generales), proyecto que fue presentado a los Estados miembros, junto con comentarios, para que formulasen sus observaciones en las distintas etapas de la negociación. ${ }^{21}$

Dada la similitud del tema de este Proyecto con la ya existente Convención de Viena sobre Relaciones Diplomáticas, fue posible a la Comisión aprobar un procedimiento acelerado, presentando el Proyecto de 71 artículos en la Asamblea General de la ONU, a título informativo y la gran mayoría de los Estados decidió que ese Proyecto debería constituir la base de un instrumento multilateral de codificación del derecho consular.

Buscando aprobar la Convención, la Comisión recomendó a la Asamblea General de la ONU celebrar una Conferencia Internacional de Plenipotenciarios en marzo de 1963, lo que desembocó en la Conferencia de las Naciones Unidas sobre Relaciones Consulares, celebrada en Viena del 04/02 al 22/04/1963, con la presencia de delegados de 95 países que, después de examinar detalladamente el texto de la Comisión, se preparó la versión definitiva para la presentación en el plenario. El 24/04/1963 la Conferencia aprueba y abre a firmas la Convención de Viena sobre Relaciones Consulares, el Protocolo Facultativo sobre la adquisición de nacionalidad y el Protocolo Facultativo sobre jurisdicción obligatoria para la solución de controversias. La Convención y ambos Protocolos entraron en vigor el 19/03/1967.

\footnotetext{
${ }^{21}$ En su $12^{\circ}$ período de sesiones, celebrado de 25/04 a 1\%/07/1960, la Comisión decidió que los artículos relativos a los cónsules de carrera también serían aplicados los honorarios, haciendo que la Comisión incluyese disposiciones más amplias y agregó algunos nuevos artículos, antes de aprobar provisionalmente el proyecto de artículos y sus comentarios.
} 
Tejidas estas palabras sobre los bastidores de la Convención de Viena sobre Relaciones Consulares, pasamos ahora al análisis del contenido material de la asistencia consular.

\section{CONTENIDO MATERIAL DE LA ASISTENCIA CONSULAR}

Antes de analizar el contenido material de la asistencia consular, se debe distinguir la asistencia consular del instituto de la protección diplomática.

Por protección diplomática (Diplomatischer Schutz) (KLEIN, 1992, p.21) o representación diplomática, se entiende el derecho del Estado de representar a sus nacionales en litigios concernientes a éstos, sobre todo en foros internacionales ${ }^{22}$. Es decir, puede el Estado, invocando el instituto de representación diplomática, representar los intereses de un nacional suyo - normalmente a pedido del propio nacional - cuando éste tiene afectados sus intereses, derechos violentados, generalmente por causa de un tercer Estado.

Como ejemplo del ejercicio de la representación diplomática puede citarse entre otros casos - el asunto juzgado por la Corte Internacional de Justicia (de 24/07/1964), "Barcelona Traction". Se trata de un juicio contra el Reino de España ${ }^{23}$. La empresa "Barcelona Traction, Light and Power Company Ltd" explotaba servicios de energía eléctrica en la Región de Cataluña. Como consecuencia de una serie de acciones por parte de España, que fue limitando sus actividades, la empresa quebró. Los accionistas eran belgas, lo que hizo que Bélgica presentara la solicitud de indemnización, ante la Corte Internacional de Justicia, contra España ${ }^{24}$.

Por asistencia consular se entiende el derecho de un individuo ${ }^{25}$, al traspasar los limites de la frontera de su Estado, de ser asistido por un representante de su

\footnotetext{
22 De acuerdo con el Art. 3o, § 10, "b", de la Convención de Viena sobre Relaciones Diplomáticas, de 1961, entre las funciones de la misión diplomática está la de "proteger en el Estado acreditado los intereses do Estado acreditante y de sus nacionales, dentro de los límites permitidos por el derecho internacional" (se subrayó).

${ }^{23}$ Vide CORTE INTERNACIONAL DE JUSTIÇA, 1999.

${ }^{24}$ Sobre el instituto de la representación diplomática, vide CANÇADO TRINDADE, 1997.

${ }^{25}$ Además de las personas físicas, también las personas jurídicas gozan del derecho a la asistencia consular.
} 
Estado de origen, principalmente en situaciones cuando se encuentre vulnerable ${ }^{26}$.

La asistencia consular envuelve, entre otras cosas, la función del consulado de actuar en la calidad de Notario y Registro Civil para la emisión de pasaportes y documentos de viaje de los nacionales del Estado del consulado, visas y documentos apropiados a los que pretenden viajar al Estado del consulado.

Analluza Bolivar (2015, p.23-24) da como ejemplo innumerables actividades que pueden ser prestadas por la jurisdicción consular:

[...] indicar médicos, clínicas ou hospitais na região; orientar em caso de sepultamento, cremação no exterior ou de traslado de restos mortais para o país de origem. Também prestar informações sobre entidades assistenciais e condições de trabalho; facilitar o contato com familiares e amigos ou alguém que lhe possa prestar ajuda, com o envio de recursos financeiros, documentos e passagens; informar os parentes mais próximos em caso de acidente ou outras emergências, e orientá-los quanto aos procedimentos adequados.

Y justamente en ese contexto se enmarca la asistencia consular en el sentido de protección al nacional que esté en situación de privación de su libertad en el exterior. La protección consular es fundamental para asegurar el respeto a los derechos fundamentales de esa persona. Para garantizar que no haya habido abuso de derecho en el momento de la prisión, coerción en la confesión. El cónsul puede aún "informar sobre a existência de serviços locais de assistência jurídica gratuita; sugerir advogados locais que possam orientar sobre serviços jurídicos; e informar, desde que autorizado pelo preso, o fato a seus familiares no seu país de origem [ou onde quer que estejam]". Todo eso con el propósito de que el derecho a una amplia defensa no sea violado, so pena hasta de nulidad procesal [BOLIVAR: 2015:24].

Por la asistencia consular, puede el preso valerse de una posibilidad de traductor, hasta para poder enterarse de su situación. ${ }^{27}$ El contenido material de la asistencia consular está intrínsecamente relacionado con las funciones consulares.

\footnotetext{
${ }^{26}$ El Artículo 5, "a" de la Convención de Viena sobre Relaciones Consulares, de 1963, determina que dentro de las funciones consulares está la de "proteger, en el Estado receptor, los intereses del Estado que envía e de sus nacionales, personas físicas o jurídicas, dentro de los límites permitidos por el Derecho internacional".

${ }^{27}$ Es común la situación de extranjeros que son detenidos y no tienen dominio del idioma del Estado donde son presos, lo que los coloca en una situación de extrema vulnerabilidad.
} 
Son varias las funciones consulares y derivan de la costumbre internacional, de tratados bilaterales y multilaterales y también del propio derecho interno de los Estados (como, por ejemplo, reglamentos consulares domésticos) (ALMEIDA, 2016, p.44).

El Artículo 5ํํㄹ de la Convención de Viena sobre Relaciones Consulares de 1963, contiene un rol enunciativo de las funciones consulares (que son ejercidas por la repartición consular). La prueba de ese rol enunciativo es que la última línea del Artículo 5, m) expresa:

Art. 5․ Las funciones consulares consistirán: $\mathrm{m}$ ) ejercer las demás funciones confiadas por el Estado que envía a la oficina consular que no estén prohibidas por las leyes y reglamentos del Estado receptor o a las que éste no se oponga, o las que le sean atribuidas por los acuerdos internacionales en vigor entre el Estado que envía y el receptor.

Un claro y actual ejemplo de asistencia consular es la política norteamericana de "tolerancia cero" a la "inmigración clandestina" 28 que llevó al absurdo de separar en la frontera hijos pequeños de sus padres y que los encerrasen, sin que pudiesen hasta comunicarse. Además de ser esas prisiones ilegales sobre diversos aspectos ${ }^{29}$, el Derecho Internacional impone a los Estados Unidos la obligación de comunicar al Estado de origen cuando un nacional suyo sea detenido. En esos casos, la autoridad consular puede:

- poner a los entes familiares detenidos en contacto;

- avisar a los demás parientes;

- visitar los locales de prisión;

- suministrar documentación, si es necesario, cuando fuere dictada una medida de deportación, etc.

\footnotetext{
28 Decimos inmigración "clandestina" porque muchos de los que entran al territorio norteamericano sin haber solicitado la visa previamente, están protegidos por el status de refugiado, debido a que su movilización es forzada; es decir, se debe a que temen por su propia vida si estuviesen permaneciendo en las localidades de origen. Hoy la expresión correcta en el Derecho Internacional es de inmigrante indocumentado - y no clandestino - ya que la situación de uno a uno debe ser analizada para saber si se trata de un inmigrante económico o de una situación de obligatoria concesión de refugio.

${ }^{29}$ Hay violación, por ejemplo, de la prohibición a la tortura.
} 


\subsection{A OPINIÓN CONSULTIVA № 16 DE LA CORTE INTERAMERICANA DE DERECHOS HUMANOS}

La 16aㅡ Opinión Consultiva de la Corte Interamericana fue emitida el 01\%10/99 y versa sobre el Derecho a la Información sobre Asistencia Consular en el contexto del Debido Proceso Legal (CORTE INTERAMERICANA DE DIREITOS HUMANOS, 1999).

Esa Opinión Consultiva fue solicitada a la Corte Interamericana de Derechos Humanos por México, debido a que unos ciudadanos mexicanos fueron condenados a pena de muerte en los Estados Unidos, sin que éste hubiese informado a esos ciudadanos sobre el derecho a la asistencia consular.

\subsection{DERECHO DE NOTIFICACIÓN CONSULAR: INTEGRA A LA LEGISLACIÓN DEL DERECHO INTERNACIONAL DE LOS DERECHOS HUMANOS.}

De acuerdo con A. A. Cançado Trindade, se trata de una Opinión Consultiva pionera, en la medida en que:

[...] colocou o Direito de notificação consular, como estipulado pelo Artigo 36(1) (b) da Convenção de Viena de 1963 sobre Relações Consulares, no universo conceitual da Legislação do Direito Internacional dos Direitos Humanos". ${ }^{30}$

4.2.1 Derecho a la información sobre la asistencia consular y el correspondiente deber de notificación consular del Estado acreditado

En esa Opinión Consultiva, la Corte "[...] declarou que o Artigo 36 da Convenção de Viena de 1963 sobre Relações Consulares reconhece ao estrangeiro sob detenção direitos - entre os quais encontra-se o direito à informação sobre

\footnotetext{
30 "Isso tem, sem dúvidas, conferido uma dimensão de direitos humanos a alguns postulados do clássico direito consular, como apontei em meu Parecer Concordante (pars. 1-35) 57 na mencionada 16aㅡ Opinião Consultiva da Corte". In CANÇADO TRINDADE, 2008, p. 41-42. Vide también: CANÇADO TRINDADE, 2007, p.1-16.
} 
assistência consular - aos quais correspondem deveres incumbidos aos Estados nos quais esses indivíduos se encontram detidos" [CANÇADO TRINDADE, 2008: 47].

Queda claro que justamente por el hecho de los extranjeros detenidos tener el derecho a la asistencia consular, a ese derecho corresponde el deber del Estado acreditado informar a esos extranjeros de ese derecho y notificar al respectivo consulado.

De acuerdo con Martha Gallardo SALA (2006, p.31-43):

Cabe a mesma autoridade a obrigação de transmitir, sem tardar, a repartição consular qualquer comunicação que o estrangeiro preso deseja que Ihe seja transmitida (parágrafo $1^{\circ}$, "b"). As autoridades locais competentes estão ainda obrigadas a informar, sem tardar, ao indivíduo de seu direito de solicitar que os funcionários consulares sejam advertidos da situação em que se encontra (parágrafo $1^{\circ}$, "b").

Vamos más allá: entendemos que la correcta interpretación de este Artículo 36 de la Convención de Viena sobre Relaciones Consulares, considerando la evolución del Derecho Internacional, obliga al Estado acreditado a notificar de inmediato a la autoridad consular, en el caso cuando algún nacional de ese consulado haya sido detenido, so pena de violar el principio del debido proceso legal.

\section{DERECHO A LA INFORMACIÓN SOBRE LA ASISTENCIA CONSULAR COMO EFECTIVIDAD DEL DEBIDO PROCESO LEGAL}

La Corte Interamericana de Derechos Humanos estableció que integra la preservación del principio del debido proceso legal, la efectividad del ejercicio de sus derechos y defensa de sus intereses "y en condiciones de igualdad procesal con otros justiciables" (parágrafo 117 da Opinião Consultiva № 16). "Assim, a notificação - a pessoas desprovidas de sua liberdade no exterior - de seu direito de se comunicar com o seu cônsul, contribui para salvaguardar sua defesa e o respeito aos seus direitos processuais (pars. 121-122). O direito individual à informação sob o Artigo 36(1)(b) da Convenção de Viena sobre Relações Consulares está, portanto, de acordo com o devido processo legal (par. 124)." [CANÇADO TRINDADE, 2008: 48]. 
De esta forma, las garantías judiciales estarían afectadas con la no observancia u obstrucción del efectivo ejercicio de este derecho.

Asimismo la Corte, además de conectar ese derecho - de información sobre la asistencia consular - con las garantías del debido proceso legal, concluyó que:

[...] sua não-observância em casos de imposição e execução de penas de morte resulta numa arbitrária privação do próprio direito à vida (nos termos do Artigo 4 da Convenção Americana de Direitos Humanos e do Artigo 6 do Pacto Internacional sobre Direitos Civis e Políticos), com todas as consequências jurídicas inerentes a violações desse tipo, ou seja, aquelas que dizem respeito à responsabilidade internacional do Estado e ao direito de reparação (par. 137). (CANÇADO TRINDADE, 2008, p.48). ${ }^{31}$

\title{
6 LA LEGISLACIÓN INTERNACIONAL DE LOS DERECHOS HUMANOS ANTE LA EVOLUCIÓN DEL PROPIO DERECHO INTERNACIONAL PÚBLICO
}

\author{
Cançado Trindade alerta ante el hecho de que esa histórica Opinión
} Consultiva No. 16 comprueba el impacto de:

\begin{abstract}
Legislação Internacional de Direitos Humanos na evolução do próprio Direito Internacional Público, especificamente pelo fato da Corte Interamericana ter sido o primeiro tribunal internacional a alertar que, em caso de nãoobservância ao Artigo 36(1)(b) da Convenção de Viena sobre Relações Consulares de 1963, isso ocorre não somente em detrimento de um Estado Parte, mas também dos seres humanos em questão." (CANÇADO TRINDADE, 2008: 48-49). ${ }^{32}$
\end{abstract}

Valério de Oliveira MAZZUOLI, al presentar la obra "Assistência Consular ao Preso Estrangeiro: fundamentos, conteúdo e efeitos", observa tres peldaños para la comprensión del derecho a la asistencia consular, en el siguiente sentido: derecho a la asistencia consular seria, al mismo tiempo, un derecho individual (primer escalón),

\footnotetext{
31 Para otras consideraciones acerca de la interpretación jurisprudencial del derecho a la asistencia consular, específicamente, los efectos del incumplimiento del derecho consular, véanse los casos juzgados por la Corte Internacional de Justicia: Breard (1998), LaGrand (1999), Avena (2003). Sobre esos casos, vide, entre otros, [ALMEIDA, 2016: p. 96 e ss].

${ }^{32}$ Opinión Consultiva no 18 (sobre la condición jurídica y los derechos de los migrantes indocumentados - 2003) va en el mismo sentido de protección del migrante en un nuevo campo, al reconocer el carácter de ius cogens al principio básico de igualdad y no discriminación "e a prevalência dos direitos inerentes a seres humanos, independentemente de seus Estados de origem". (CANÇADO TRINDADE, 2008, p.49).
} 
integraría el principio del debido proceso legal (segundo escalón) y también sería un derecho humano (tercer escalón).

En ese sentido, es pertinente la siguiente afirmación de Valério de Oliveira Mazzuoli: "a assistência consular ao preso estrangeiro contribui para o processo de humanização do Direito Internacional Público e do Direito Consular". ${ }^{33}$

Como bien afirma Patrícia JERÓNIMO: "Todos os Estados têm diásporas mais ou menos numerosas e mais ou menos espalhadas pelo globo, do mesmo modo que todos os Estados têm nos seus territórios, a título temporário ou permanente, regular ou irregular, indivíduos estrangeiros e apátridas". ${ }^{34}$ Todos los Estados del mundo están envueltos de algún modo en los flujos migratorios como Estados de origen, de destino y/o de tránsito. Las migraciones internacionales contemporáneas son marcadas por ese carácter global.

Existen varios instrumentos en el Derecho Internacional - principalmente en el Derecho Internacional de los Derechos Humanos - que imponen a los Estados el deber de proteger y prestar asistencia a sus nacionales en el mundo y el deber de los Estados de respetar los derechos fundamentales de la persona humana, incluyendo las garantías procesales en el proceso penal, de los extranjeros y apátridas que se encontraren en su territorio.

El ítem 4 del Capítulo III de la obra ya citada de Jeison Batista de Almeida es justamente titulado como "Assistência Consular ao Preso Estrangeiro e sua Contribuição para o Processo de Humanização do Direito Internacional Público e do Direito Consular". [ALMEIDA, 2016:167]. Almeida entiende que los derechos fundamentales de la persona humana no son datos, pero si "una construcción" y se refleja en la necesidad de protección del individuo ante los abusos del Estado.

Ese entendimiento es corroborado por Flávia PIOVESAN, cuando argumenta:

[o] sistema internacional de proteção dos direitos humanos constitui o legado maior da chamada "Era dos Direitos", que tem permitido a internacionalização dos direitos humanos e a humanização do Direito Internacional (PIOVESAN, 2017: 349).

${ }^{33}$ Valério de Oliveira Mazzuoli, "Apresentação" do livro: ALMEIDA, 2016, p. 8.

${ }^{34}$ Patrícia JERÓNIMO, "Prefácio" à obra de ALMEIDA, 2016, p. 9. 


\section{CONCLUSION}

Pese a la redacción del Artículo 36 de la Convención de Viena sobre Relaciones Diplomáticas contiene una disposición literal en el sentido de que solamente si el preso extranjero lo requiera, deberá el Estado detentor notificar a su consulado, por todos los argumentos supra desarrollados, se concluye que es más que evidente que independientemente de que el preso lo solicite o no, esa notificación es obligatoria.

Corroborando el criterio de que el Estado que detiene un preso extranjero está obligado a garantizarle el derecho a la asistencia consular, puede afirmarse lo que sigue, a modo de consideraciones finales:

- el derecho a la asistencia consular es un derecho fundamental del ser humano;

- como derecho fundamental del ser humano, es inalienable;

- y aún, por ser un derecho fundamental del ser humano, además de inalienable, prescinde de declaración de su titular para que la materialidad de ese derecho pueda ser aprovechada;

- en el caso que un extranjero haya sido detenido y juzgado sin que haya sido asegurada la asistencia consular, el proceso judicial está afectado por vicio de nulidad de la decisión judicial;

- por consiguiente, la decisión judicial condenatoria del preso extranjero desasistido de su derecho a la asistencia consular, genera responsabilidad internacional del Estado infractor.

El debido disfrute del derecho a la asistencia consular por parte de presos extranjeros y la interpretación de la jurisprudencia de cortes internacionales sobre el tema, es una cristalina constatación de la evolución del Derecho internacional contemporáneo.

De un Derecho internacional clásico, reflejo de una sociedad internacional formada por Estados titulares de una soberanía entendida como un poder absoluto e indelegable, en una sociedad internacional en yuxtaposición, en la cual un Estado lleva en cuenta la existencia de otros sólo para pautar su comportamiento considerando sus intereses exclusivistas, se pasa a un Derecho internacional fruto de 
una sociedad interrelacionada, marcada por la existencia de principios como la igualdad soberana de los Estados, principios de cooperación, etc.

Hoy, más que nunca, el Derecho Internacional no sólo protege a los individuos asegurándoles los derechos humanos, como dispone de instrumentos para garantizar que esos derechos permanezcan no sólo en los planos de existencia y validez, sino principalmente en el plano de la eficacia.

De todo lo supra mencionado, se desprende que el derecho a la asistencia consular es un principio de Derecho internacional y como principio, es de ius cogens, quedando el Estado infractor sujeto a la responsabilidad internacional. Esto acarrea el deber de indemnizar a los lesionados, sea mediante decisión interna del propio poder judicial del Estado infractor, sea mediante decisión de una instancia internacional, por medio del instituto de representación diplomática, etc.

\section{REFERENCIAS}

AGBAKWA, Shedrack Chukwuexœka, Retrieyng the rejected stone: rethinking the marginalization of the economic, social and cultural rights under the african charter on human and people's rights, Dalhousie University Halifax, Nova Scotia, Canada: National Library of Canada. August 2000 (dissertação de mestrado). Disponíble en: http://www.collectionscanada.gc.ca/obj/s4/f2/dsk2/ftp01/MQ57181.pdf [acceso en 26/06/2018]

ALMEIDA, Jeison Batista de. Assistência consular ao preso estrangeiro: fundamentos, conteúdo e efeitos. Curitiba: Editora Prismas, 2016.

ANTOKOLETZ, Daniel. Tratado teorico y practico de derecho diplomatico y consular - con referencias especiales a la República Argentina y a las demás Repúblicas Americanas, Tomo I (Derecho Diplomatico), Buenos Aires: Editorial Ideas, 1948.

BOBBIO, Norberto. A Era dos Direitos. Rio de Janeiro: Campus. 1992.

BOLIVAR, Analluza. Assistência Consular ao preso estrangeiro: casos internacionais e o Brasil. Curitiba: Appris, 2015.

BRITO, Wladimir. Direito Consular. Coimbra: Coimbra Editora, 2004.

CAHIER, Philippe, Derecho Diplomático Contemporaneo, (título original: Le Droit Diplomatique Contemporain, 1962) trad. de Jose-Vicente TORRENTE, Marcelino 
OREJA, Julio GONZALES-CAMPOS, Madrid/México/Buenos Aires/Pamplona, Ediciones Rialp S. A., 1965.

CANÇADO TRINDADE, Antonio Augusto. 0 esgotamento dos recursos internos no Direito Internacional. Brasília: UnB, 1997.

. "Seminário Direitos Humanos das Mulheres: A Proteção Internacional" Evento Associado à $V$ Conferência Nacional de Direitos Humanos, ocorrido na Câmara dos Deputados (Brasília - DF), en 25 de mayo de 2000. Disponíble en: http://www.dhnet.org.br/direitos/militantes/cancadotrindade/cancado bob.htm [acceso en 26/06/2018]. Citado nesta obra como [CANÇADO TRINDADE:2000].

Tratado de Direito Internacional dos Direitos Humanos. Volumes I ( $2^{\mathrm{a}}$

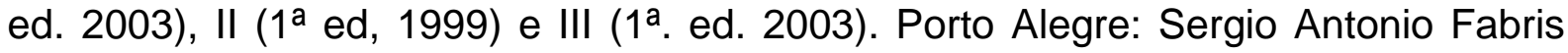
Editor, 1999-2003.

$2006 \mathrm{a}$.

A humanização do Direito Internacional. Belo Horizonte: Del Rey,

- "Apresentação" à obra de PIOVESAN, Flávia. Direitos Humanos e o direito Constitucional Internacional. $7^{\mathrm{a}}$ ed., São Paulo: Saraiva, 2006b.

. "The Humanization of Consular Law: The Impact of Advisory Opinion n. 16 (1999) of the Inter-American of Human Rights on International Case-Law and Practice", 4 Chinese Journal of International Law (2007) pp. 1-16.

. "Desarraigamento e a proteção dos migrantes na legislação internacional dos direitos humanos", tradução de Gabriel Gualano de Godoy. In Revista da Faculdade de Direito - UFPR, Curitiba, n. 47, p. 29-64, 2008. Disponíble en: http://ojs.c3sl.ufpr.br/ojs/index.php/direito/article/viewFile/15734/10440 [acceso en 25/02/2016].

COMISSÃO DE DIREITO INTERNACIONAL DA ONU. Draft Articles on Consular Relations, with $\quad$ commentaries, $1961 . \quad$ http://legal.un.org/ilc/texts/instruments/english/commentaries/9 2 1961.pdf [acceso en $25 / 06 / 2018]$

CORTE INTERAMERICANA DE DIREITOS HUMANOS. Opinião Consultiva $\boldsymbol{n}^{\circ} 16$. Disponíble en: https://www.oas.org/dil/Advisory_Opinion_OC_16_eng.doc [acceso en 31/05/2018]. También en: http://www.corteidh.or.cr/docs/opiniones/seriea 16 esp.pdf [acceso en: 01/06/2018].

CORTE INTERNACIONAL DE JUSTIÇA. Case Barcelona Traction, Light and Power Company, Limited (Belgium v. Spain) (New Application: 1962). Disponíble en: http://www.icj-cij.org/en/case/50/judgments [acceso en 31/05/2018].

DHNET. Cançado Trindade Questiona a Tese de "Gerações de Direitos Humanos" de Norberto Bobbio. 2000. Disponível em: 
http://www.dhnet.org.br/direitos/militantes/cancadotrindade/cancado bob.htm. Acesso em: 26/06/2018.

FERRARA, Francesco, Manuale di Diritto Consolare, Padova: Cedam, 1936.

FLORIO, Franco. Nozioni di Diplomazia e Diritto Diplomatico, 2ª . ed., Milano: Giuffrè, 1978.

FRANCHINI NETTO, Miguel. A Evolução da Diplomacia: antiga e nova técnica, São Paulo: RT, 1946.

GENET, Raoul. Traité de Diplomatie et de Droit Diplomatique, Tome I, II e III, Paris: Pedone Éditeur, 1931.

GIRY, A. Manuel de Diplomatique - diplomes et chartes - chronologie technique eléments critiques et parties constitutives de la tenuer des chartes les chancelleriesles actes privés, Paris: Librairie Hachette et Cie, 1894.

GÓMEZ ROBLEDO, Juan Manuel. Convención de Viena sobre Relaciones Consulares. United Nations Audiovisual Library of International Law. United Nations, 2009. Disponíble en: http://legal.un.org/avl/pdf/ha/vccr/vccr_s.pdf [acceso en 31/05/2018].

KLEIN, Eckart. Diplomatischer Schutz im Hinblick auf Konfiskationen deutschen Vermögens durch Polen. Bonn: Kulturstiftung der deutschen Vetriebenen, 1992.

LIMA, George Marmelstein. Críticas à teoria das gerações (ou mesmo dimensões) dos direitos fundamentais. In Jus Navegandi n. 173, 26/12/2003. Disponíble en: https://jus.com.br/artigos/4666/criticas-a-teoria-das-geracoes-ou-mesmo-dimensoesdos-direitos-fundamentais [acceso en 26/06/2018].

MORENO PINO, Ismael, La Diplomacia - aspectos técnicos y prácticos de su ejercicio profesional, México: Secretaría de Relaciones Exteriores/Fondo de Cultura Económica, 2001.

NASCIMENTO E SILVA, Geraldo Eulálio do. Diplomacia e Protocolo, São Paulo: Gráfica Record Editora, 1969.

NICOLSON, Harold, La Diplomacia, $2^{\mathrm{a}}$ ed., trad. de Adolfo Alvarez Buylla (trad. da edição inglesa de 1939), México: Fondo de Cultura Econômica, 1950.

PIOVESAN, Flávia. Direitos Humanos e o direito Constitucional Internacional. $7^{\underline{a}}$ ed., São Paulo: Saraiva, 2006.

PIOVESAN, Flavia. Internacionalização dos direitos humanos e humanização do direito internacional: desafios contemporâneos. Boletim da Sociedade Brasileira de Direito Internacional - Órgão Oficial da Sociedade Brasileira de Direito Internacional - SBDI, ano CIII, n. 125-130, v. 103, julho/dezembro 2017, p. 349-384. 
SALA, Martha Gallardo. Origem, conceito e aplicação da assistência consular a presos estrangeiros. Lex. Revista do Direito Brasileiro, v. 23, p. 31-43, 2006. Disponíble en: http://sisnet.aduaneiras.com.br/lex/doutrinas/arquivos/110607.pdf, p. 1-15 [acceso en 25/02/2016].

Assistência consular a presos estrangeiros nos Estados Unidos: o caso do México. 2009. 167f. Dissertação (Mestrado) - Programa de Pós-Graduação em Integração da América Latina, Universidade de São Paulo, São Paulo, 2009. p.2324.

SEMINÁRIO DIREITOS HUMANOS DAS MULHERES: A Proteção Internacional Evento Associado à V Conferência Nacional de Direitos Humanos. Câmara dos Deputados (Brasília - DF), 25 de maio de 2000. Disponíble en: http://www.dhnet.org.br/direitos/militantes/cancadotrindade/cancado bob.htm [acceso en 26/06/2018].

SOARES, Guido Fernando Silva. Órgão dos Estados nas Relações Internacionais: formas da diplomacia e as imunidades, Rio de Janeiro: Forense, 2001.

VASAK, Karel. A 30-year Struggle: the sustained efforts to give force of law to the Universal Declaration of Human Rights. The UNESCO Courier, 30th year (Souther Africa at groups with racismo). UNESCO: Paris, november 1977. Disponíble en: http://unesdoc.unesco.org/images/0007/000748/074816eo.pdf\#nameddest=48063 [acceso en 26/06/2018].

VASAK, Karel. For the Third Generation of Human Rights: The Right of Solidarity, Inaugural Lecture, Tenth Study Session, International Institut of Human Rights, July 1979.

VIEGAS LIQUIDATO, Vera Lúcia. Direito Diplomático: a prática das imunidades dos agentes diplomáticos. Osasco: Edifieo, 2014.

. Direito à liberdade e ao due process of law: Direito do preso estrangeiro à Assistência Consular. In: GUERRA, Sidney; PINTO, Felipe Chiarello de Soza; GUERRA, Caio Grande (Org.). 70 anos da Declaração Universal dos Direitos Humanos: olhares e desafios. ${ }^{\circ}$ ed. Curitiba: Instituto Memória, 2018, p. 319-337. 